\title{
sciforum
}

Conference Proceedings Paper

\section{Impacts of Atmospheric Rivers in extreme precipitation on the European Macaronesian islands}

\author{
Alexandre M. Ramos ${ }^{1}$, Ricardo M. Trigo ${ }^{1}$, Ricardo Tomé ${ }^{1}$, Margarida L.R. Liberato ${ }^{1,2}$ \\ Published: 06/11/2017 \\ Academic Editor: Rosana Nieto-Ferreira \\ 1 Instituto Dom Luiz, Universidade de Lisboa, Lisbon, Portugal \\ 2 Escola de Ciências e Tecnologia, U. de Trás-os-Montes e Alto Douro, Portugal \\ * Correspondence: amramos@fc.ul.pt
}

\begin{abstract}
Extreme precipitation events in Europe have major socio-economic impacts. In recent years, a number of works have shed new light on the role played by Atmospheric Rivers (ARs) in the occurrence of extreme precipitation events in Europe. The flash flood event that occurred on the Madeira Island on the 20 February 2010 with a death toll of near 50 was due an AR. Despite the frequent occurrence of extreme events in the European Macaronesia Archipelagos (Azores, Madeira and Canary Islands) no comprehensive study has been made concerning the relationship between ARs and extreme precipitation. We have analysed the recorded daily precipitation from various stations located in the different Macaronesia islands. Regarding the ARs database we have used the method a global detection scheme applied to four different reanalysis datasets. It is shown that the ARs influence over extreme precipitation (above the $90^{\text {th }}$ percentile) is higher in the Azores islands when compared with Madeira or Canary Islands. In Azores, for the most extreme precipitation days the presence of ARs is particularly significant while for Madeira the importance of the ARs is reduced. For the Canary Islands, the occurrence of ARs on extreme precipitation is even lower.
\end{abstract}

Keywords: Macaronesian Archipelagos; Extreme Precipitation; Atmospheric Rivers; Extended Winter Months

\section{Introduction}

In the western Atlantic half of the Iberian Peninsula (IP), extreme precipitation events during the winter months have been associated historically with major socio-economic impacts such as flooding, landslides, extensive property damage and human casualties. These events are usually associated to low pressure systems of Atlantic origin [1, 2,3].

The analysis of the contribution of ARs to extreme precipitation events has been restricted to a few areas of the world, with a strong focus on the eastern North Pacific and their associated impacts on the contiguous North American west coast [4-5]. ARs are relatively narrow regions of concentrated water vapour (WV) responsible for anomalous WV transport. Over Europe, the large amount of WV that is usually transported by these ARs can also lead to extreme precipitation events and flooding as described for a few specific extreme events [3,6] but also in a climatological context [7-8]. [9] have shown a strong relationship between ARs and the occurrence of annual maxima precipitation days in Western Europe. This relationship is especially strong along the western European seaboard, with 
The 1st International Electronic Conference on the Hydrological Cycle (CHyCle-2017), 12 - 16 November 2017; Sciforum Electronic Conference Series, Vol. 1, 2017

some areas having eight of their top 10 annual maxima precipitation days related to the occurrence of ARs.

Regarding the European Macaronesian Archipelagos, the impact of an ARs was responsible for the flash flood event that occurred on the Madeira Island on the 20 February 2010 with a death toll of near $50[10,11]$. In addition a systematic study was also performed for a 10 year period in the Madeira Island, where the association between extreme precipitation and ARs (derived from satellite imagery) has also been established [12].

However, as far we are aware, no long-term systematic studies have been done for the three European Macaronesian Archipelagos (Azores, Madeira and Canary Islands). To do so, we have used a precipitation dataset covering several stations located in various islands of each archipelago. In addition, an ARs global database using different reanalysis datasets was used in order to access the days of occurrence of the ARs in each archipelago. Therefore, the main objectives of this work is to evaluate the impacts of ARs in extreme precipitation on the European Macaronesian Archipelagos for a 30 year period between 1980 and 2010 for the extended winter months (October to March).

\section{Data and Methods}

\subsection{Precipitation Dataset}

The precipitation data includes daily data from 31 climatological weather stations covering the 1980 and 2010 period (for the extended winter months, October to March) representative the three European Macaronesian archipelagos. Overall, these stations were chosen based on a combination of tests for data length, completeness, quality and homogeneity. Regarding the Madeira and Azores Islands the dataset were retrieved from the Portuguese Met Office (IPMA) while the Canary dataset was retrieved from the Spanish Met Office (AEMET).

For the Madeira and Porto Santo Islands we have used 8 weather stations ( 7 in Madeira Island and 1 in Porto Santo) and it's locations. Regarding the Azores, 16 weather stations were used embracing all the 9 islands. From the western group ( 2 islands), two weather stations were used, while from the central group ( 5 islands) we managed to retrieve 8 weather stations. Finally from the eastern group ( 2 islands), 6 weather stations were analysed. Finally the Canary dataset consists of 6 weather stations prevenient from 5 islands (La Palma; Tenerife; Gran Canaria; Fuerte Ventura and Lanzarote). Due to the limited nature of this proceedings we will limit the analysis to one island (and some specific weather stations) of each archipelago. The weather stations analysed here are summarized in Table 1. For each weather station we have calculated the deciles of the available data (ignoring values below $1 \mathrm{~mm} / 24 \mathrm{~h}$ ). These deciles are divided in ten equally spaced bins for later comparison with the ARs datasets.

\subsection{Atmospheric Rivers Dataset}

The ARs detection scheme was developed at the global scale by [13]. For this method, there is no need of a reference starting point to search for the ARs, instead, the method isolates contiguous regions of the word of enhanced IVT exceeding a certain IVT threshold $\left(>85^{\text {th }}\right.$ percentile or $100 \mathrm{~kg} \mathrm{~m}^{-}$ ${ }^{1} \mathrm{~S}^{-1}$, whichever is greater). Each of these regions will be subsequently analysed for the geometry requirement of length $>2000 \mathrm{~km}$, length/width ratio $>2$ and other considerations indicative of ARs conditions [14]. For additional information regarding the methodology please refer to [13]. The databases used here were provided kindly provided by these authors. 
The 1st International Electronic Conference on the Hydrological Cycle (CHyCle-2017), 12 - 16 November 2017; Sciforum Electronic Conference Series, Vol. 1, 2017

Table 1. Information regarding the weather stations analysed for each Archipelago

\begin{tabular}{|c|c|c|c|}
\hline Madeira archipelago & Latitude & Longitude & Height (m) \\
\hline Funchal/Madeira & 32.65 & -16.89 & 58 \\
\hline Machico/Madeira & 32.72 & -16.77 & 160 \\
\hline Santo da Serra/Madeira & 32.72 & -16.81 & 668 \\
\hline Santana/Madeira & 32.80 & -16.88 & 380 \\
\hline & & & \\
\hline Azores archipelago & Latitude & Longitude & Height (m) \\
\hline Lages/Terceira & 38.75 & -27.08 & 53 \\
\hline Angra/Terceira & 38.67 & -27.28 & 74 \\
\hline Altares/Terceira & 38.78 & -27.30 & 130 \\
\hline Agualva/Terceira & 38.75 & -27.18 & 160 \\
\hline & & & \\
\hline Canary archipelago & Latitude & Longitude & Height (m) \\
\hline Izaña/Tenerife & 28.30 & -16.49 & 2367 \\
\hline Rodeos/Tenerife & 28.47 & -16.32 & 617 \\
\hline Santa Cruz/Tenerife & 28.45 & -16.25 & 36 \\
\hline
\end{tabular}

The global ARs database consists of four different sets, each one corresponding to the application of the method of [13] to four different reanalysis datasets (ERA-Interim with $1.5^{\circ} \times 1.5^{\circ}$ spatial resolution; CFSR with $0.5^{\circ} \times 0.5^{\circ}$ spatial resolution; MERRA2 with $0.625^{\circ} \times 0.5^{\circ}$ spatial resolution and NCEP/NCAR with $2.5^{\circ} \times 2.5^{\circ}$ spatial resolution) between 1980 and 2010 for the winter extended months (October to March) at a 6-hourly temporal resolution. The use of multiple reanalysis is more appropriate than a single reanalysis in order to ensure more robust results, since the European Macaronesian islands are relatively small and therefore changes in the resolution of the reanalysis datasets, among others, could influence the results.

\subsection{Relationship between Atmospheric Rivers and Precipitation}

In order to extract the ARs that influence each island, we have, located the nearest grid point of the different reanalysis datasets relative to the centre of each island. Afterwards for each 6-hour time step between 1980 and 2010 we check if that grid point was classified as an AR, obtaining a list of days for each island that was under the ARs influence.

Regarding the precipitation days, as mention in section 2.1, we have divided the precipitation distribution for each weather station in deciles (ten equally spaced percentile bins, ignoring values below $1 \mathrm{~mm} / 24 \mathrm{~h}$ ). So the first decile bin would include the days that have precipitation between the 0 percentile and 9 percentile, while the second bin would include precipitation days falling between $10^{\text {th }}$ percentile and $19^{\text {th }}$ percentile till the last decile bin which will include the most extreme days $>90^{\text {th }}$ percentile.

Finally, for each weather station, and for each decile bin, we cross-check the dates between the precipitation dates within each bin, and if they were associated to an ARs day for each of the 4 databases. 
The 1st International Electronic Conference on the Hydrological Cycle (CHyCle-2017), 12 - 16 November 2017; Sciforum Electronic Conference Series, Vol. 1, 2017

\section{Results}

Due to the limited nature of this proceedings we will limit the analysis to one island (and some specific weather stations) of each archipelago. Therefore in the following sections we will only analyse the results relative to the Terceira Island in the Azores, Madeira Island in the Madeira archipelago and Tenerife Island in the Canary.

\subsection{ARs Frequency}

For each Island, we have extracted the number of ARs time steps for each one of the reanalysis (see section 2.3). The results are summarized in Figure 1 for the Terceira, Madeira and Tenerife islands. On average the Terceira Island presents higher frequency of ARs time steps compared to the other two islands (Madeira and Tenerife).
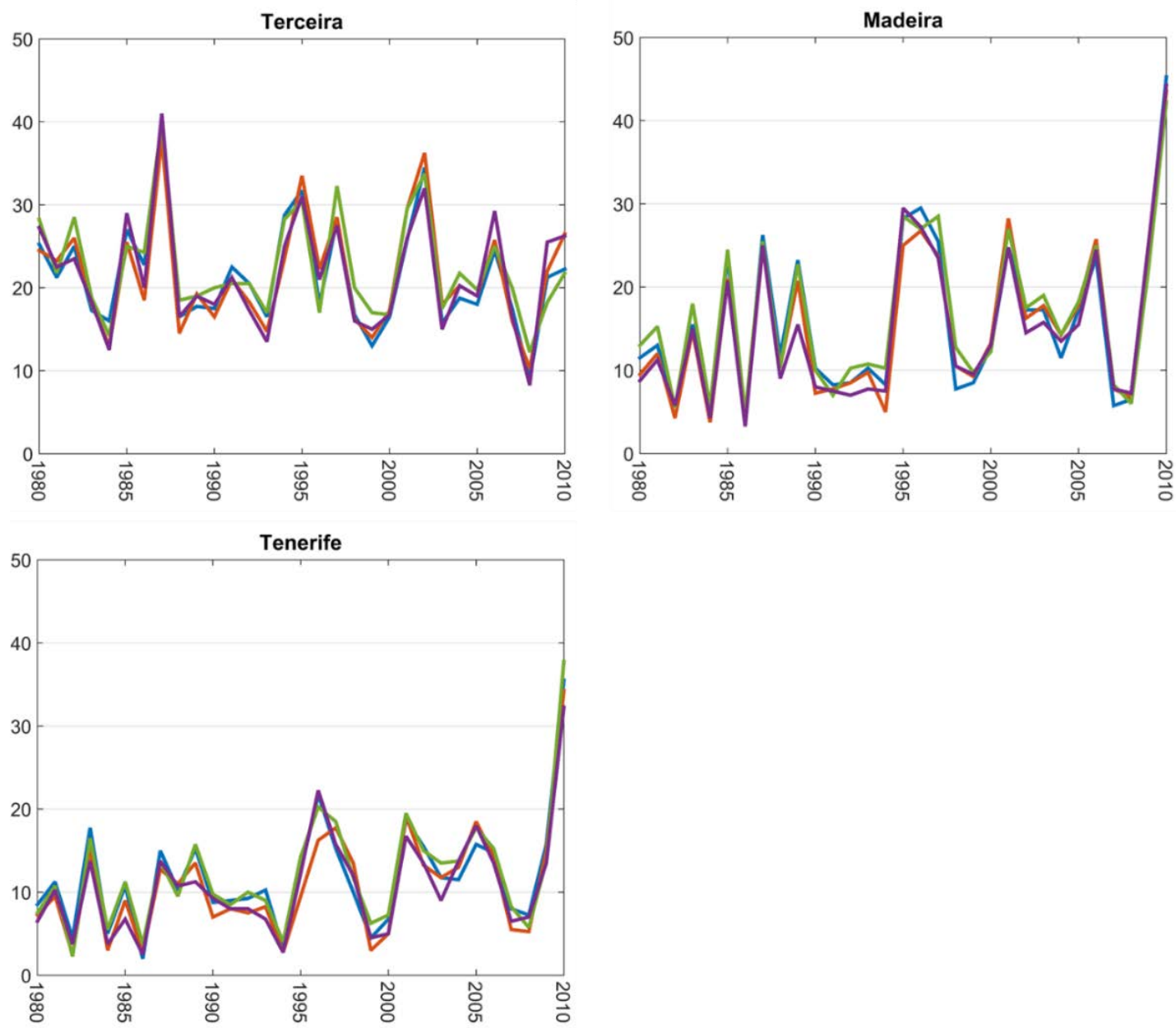

Figure 1. The frequency of the ARs time steps per extended winter for each of the 4 reanalysis (ERAInterim (blue line); CFSR (red line); MERRA2 (green line) and NCEP/NCAR (purple line) for Terceira island (Azores), Madeira island (Madeira archipelago) and Tenerife island (Canary).

In addition, it is possible to observe a strong inter-annual variability for all three islands with a maximum/minimum spanning between circa 10 and 40 ARs time steps for the extended winter months in Terceira Island. For the eastern most islands (Madeira and Tenerife) the intra-annual variability is also present with a clear ARs maximum activity in the 2010 extended winter peaking to near 45 and near 40 ARs time septs respectively.

In addition, when analysing the results of Figure 1 it is possible to state that despite the use of the 4 different reanalysis (ERA-Interim (blue line); CFSR (red line); MERRA2 (green line) and 
The 1st International Electronic Conference on the Hydrological Cycle (CHyCle-2017), 12 - 16 November 2017; Sciforum Electronic Conference Series, Vol. 1, 2017

NCEP/NCAR (purple line), no significant differences are found in terms of ARs frequencies for all the three islands.

\subsection{Azores Archipelago (Terceira Island)}

In Figure 2 we show the association between the ARs occurrence and the precipitation in four different weather station in the Terceira island (see section 2.3) for the top decile precipitation bins starting on the $6^{\text {th }}$ decile ( $50^{\text {th }} 59^{\text {th }}$ percentiles) and ending in the most extreme precipitation days in the last decile $\left(>90^{\text {th }}\right.$ percentile). For all weather stations assessed we can observe that in the $6^{\text {th }}$ decile bin of the precipitation has $40 \%$ of days with ARs occurrence. These values increase for the higher decile ( $>90^{\text {th }}$ percentile) bin of precipitation reaching values near $70 \%$ of the most extreme precipitation days being associated with ARs in Lajes and Agualva locations. Regarding Angra and Altares weather stations the importance of ARs in explaining the most extreme precipitation days is reduced to near 55\% in Angra and below 50\% in Altares. Additionally, no significant differences are found in terms of results when analysing the four different reanalysis, although the NCEP (purple) provides consistently lower values.
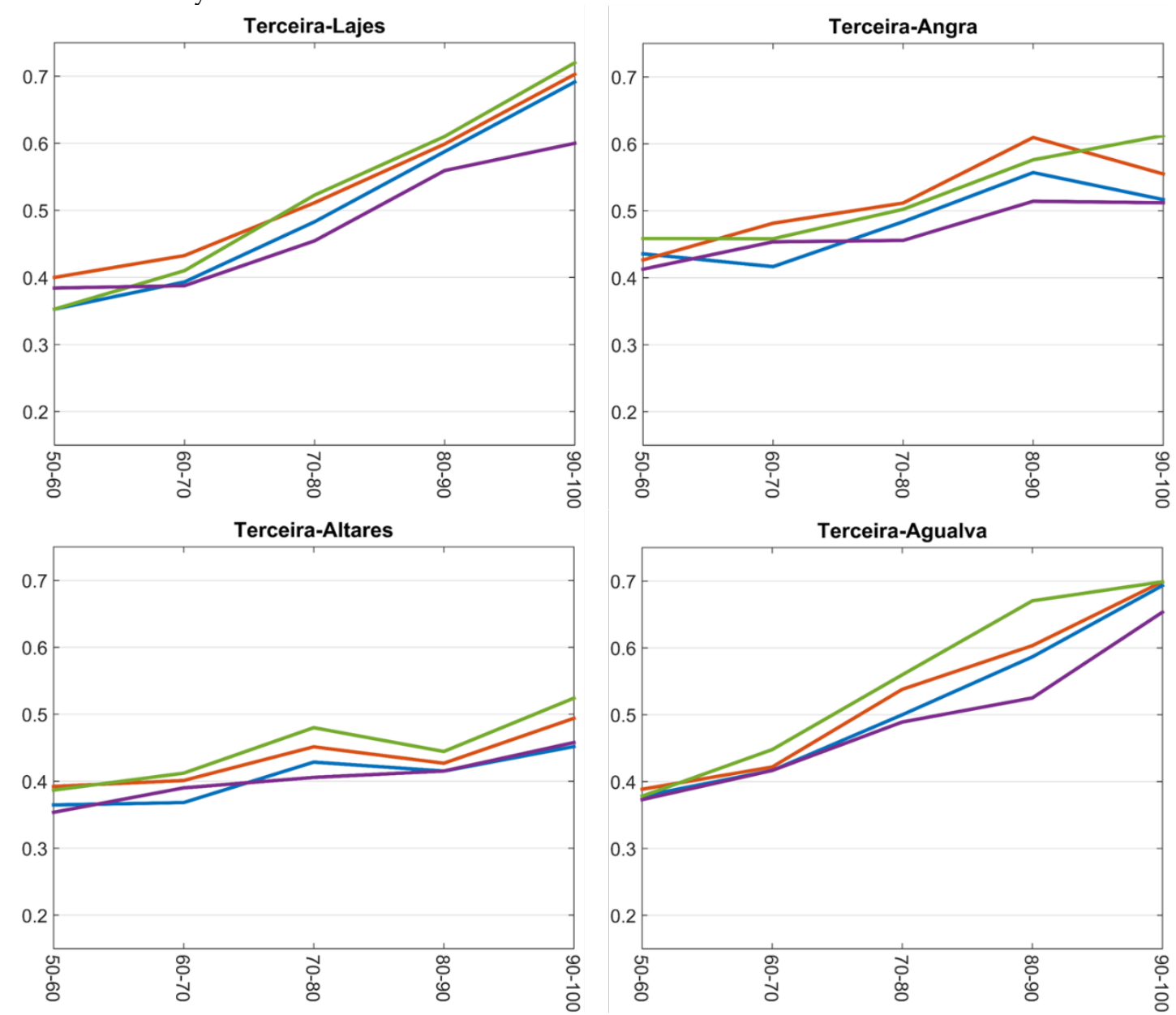

Figure 2. The percentage of days associated with ARs for the precipitation days (extended winter) that are included in the respective precipitation decile bin for each of the 4 reanalysis (ERA-Interim (blue line); CFSR (red line); MERRA2 (green line) and NCEP/NCAR (purple line). The analysed locations in Terceira Island are: Lajes; Angra; Altares and Agualva.

\subsection{Madeira Archipelago (Madeira Island)}

The same analysis was applied to four stations located in the Island of Madeira (Funchal, Machico, Santana and Santo da Serra). The relationship between the ARs occurrence and intense precipitation events tend to be weaker as those found for the Azores (Figure 3). In three of the 
considered weather stations (Machico, Santana and Santo Serra) the values rise from 20\% of ARs in the $6^{\text {th }}$ decile bins to values of $40-50 \%$ of ARs days in the higher percentiles bins. In the capital station of Funchal the values are reasonably higher with values up to $60 \%$ in the last decile ( $>90^{\text {th }}$ percentile) and for the MERRA 2 reanalysis. In the case of Funchal it must be stress that the use of the different reanalysis dataset have influence in the results especially in the $>90^{\text {th }}$ percentile bin with values ranging from $45 \%$ in the NCEP/NCAR to $60 \%$ in the MERRA2.
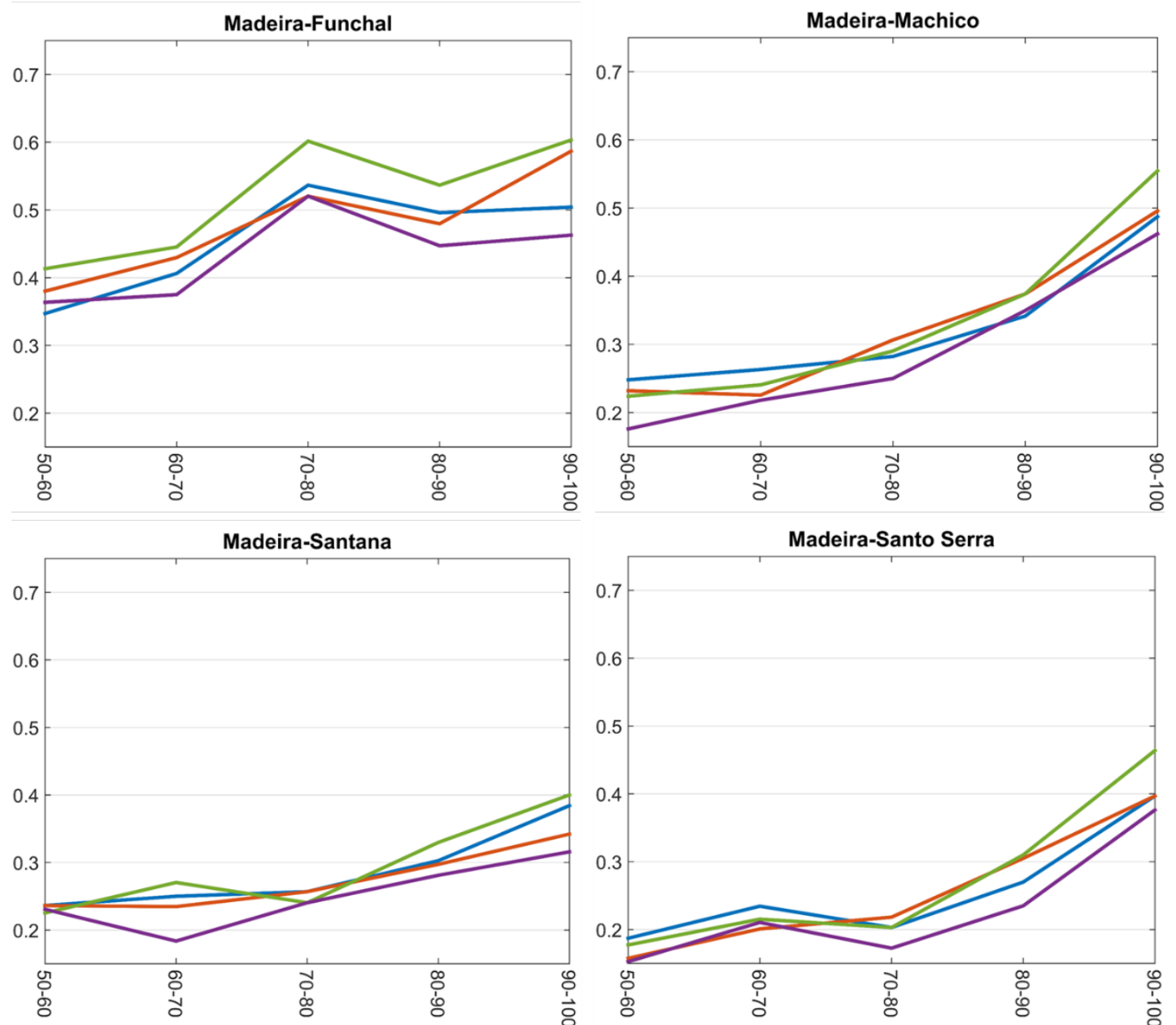

Figure 3. The percentage of days associated with ARs for the precipitation days (extended winter) that are included in the respective precipitation percentile bin for each of the 4 reanalysis (ERAInterim (blue line); CFSR (red line); MERRA2 (green line) and NCEP/NCAR (purple line). The analysed locations in Madeira Island are: Funchal; Machico; Santana and Santo da Serra.

\subsection{Canary Archipelago (Tenerife Island)}

Similar to results described for the island of Madeira, when analysing the Tenerife Island (Figure 4) regarding the relations between ARs and precipitation is lower than what was found in the Terceira Islands. Values vary between $30 \%$ in the lower decile bins and can reach values over $50 \%$ in the bins with the highest precipitation days in the last decile ( $>90^{\text {th }}$ percentile). The case of Rodeos is the exceptions with the days included in the higher deciles being associated with ARs in near $60 \%$ of the days for the ERA-Interim; CFSR; and NCEP/NCAR while for the MERRA2 its association is higher up to $65 \%$. 
The 1st International Electronic Conference on the Hydrological Cycle (CHyCle-2017), 12 - 16 November 2017; Sciforum Electronic Conference Series, Vol. 1, 2017
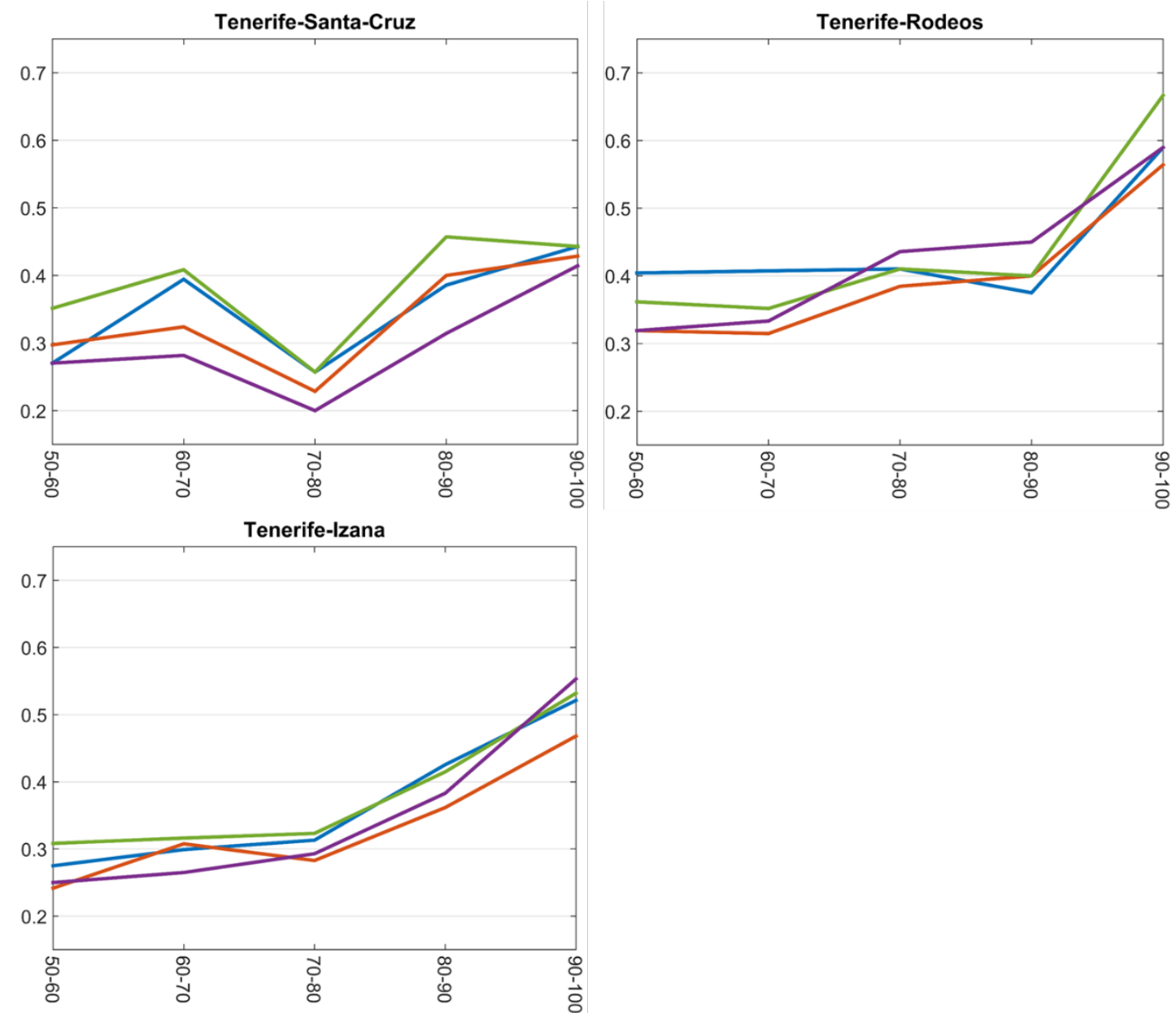

Figure 4. The percentage of days associated with ARs for the precipitation days (extended winter) that are included in the respective precipitation deciles bin for each of the 4 reanalysis (ERA-Interim (blue line); CFSR (red line); MERRA2 (green line) and NCEP/NCAR (purple line). The analysed locations in Tenerife Island are: Santa Cruz; Rodeos and Izana.

\section{Discussion}

The importance of the ARs in explaining the extreme precipitation on the European Macaronesian islands was shown in section 3. However as mentioned in section 3.1 the number of ARs that strike each Archipelago is different. The Azores are located over the North Atlantic often affected by the passage of cold fronts associated with the storm track in the North Atlantic [15]. Since the ARs are usually associated with the low-level jet stream ahead of the cold front of an extratropical cyclone [5] and therefore can be highly relevant when explaining the most extreme precipitation cases. This was shown here only for the Terceira Island but we have obtained similar results for the other islands of the Azores.

Regarding the Madeira and Canary the frequency of ARs is relatively lower when compared with the Azores due to the fact that the storm track is weaker than the one found in the Azores sector. In addition, given its southern location, both archipelagos are also under the influence of other synoptic systems, including Mesoscale Convective systems or cut off low system that help to explain the extreme precipitation that occur. In any case it was shown by [12], for a 10 years period (September 2002 to November 2012) that in the Madeira Island, the relevance of the contribution of ARs to extreme precipitation.

In sections 3.2 to 3.4 we investigate the relationship between ARs and extreme precipitation between 1980 and 2010 on the European Macaronesian islands (through the examples the Terceira, 
The 1st International Electronic Conference on the Hydrological Cycle (CHyCle-2017), 12 - 16 November 2017; Sciforum Electronic Conference Series, Vol. 1, 2017

Madeira and Tenerife Island). Our results for the Madeira confirm the results found for [12] that the island is sometimes struck by an AR capable of producing extreme precipitation especially for Funchal and Machico. It also shows that the winter of 2010 was highly unusual for the Madeira with many more ARs than the usual range of variability

Regarding the Azores our results are novel and clearly indicate that the presence of an ARs is import in explaining the extreme precipitation that occurs in the Terceira Island as well as in other islands of the Azores.

Moreover, when analysing the different locations on the Tenerife island one result that strikes clearly is that the importance of the ARs in explaining the extreme precipitation is higher in the Rodeos and in Santa Cruz or Izana. This can be explained by the topography and the relative position of the each location in Tenerife. While Rodeos is located in the northern part of the Island (altitude of $617 \mathrm{~m}$ ), without any mountain range in the vicinity and thus can be stricken directly by the ARs. On the contrary and despite being located at an altitude of $2367 \mathrm{~m}$ the Izana weather station is positioned on the eastern side of the Teite volcano and therefore affected by its shadow effect since the ARs tend to have a SW-NW direction.

\section{Conclusions}

Extreme precipitation events in western Europe during the extended winter months have major socioeconomic impacts such as floods, landslides, extensive property damage, and losses of life, as shown in some long-term assessment studies $[8,16]$ and several studies that focused on extreme events $[1,3,17]$. Regarding the European Macaronesian archipelagos no comprehensive studies were done to study the impact of the ARs on extreme precipitation. The only systematic study that we are aware of was done only for a 10 years period in the Madeira Island, where the association between extreme precipitation and ARs (derived from satellite imagery) has also been established [12]. The necessity to establish this link on a longer perspective was made urgent after the unusual winter of 2010 and in particular as a consequence of an AR that was responsible for the many flash flood events that occurred on the Madeira Island on the 20 February 2010 with a deal toll of near 50 [10, 12]. Therefore the main goal of this work was to evaluate the impacts of ARs in extreme precipitation on the European Macaronesian Archipelagos for a 30 year period between 1980 and 2010 for the extended winter months (October to March).

To achieve this objective, we have used daily precipitation dataset in most of the islands of the three archipelagos in order to access the dates where extreme precipitation occurred taking into account the decile bins.

Moreover, four ARs global databases [13] corresponding to 4 different reanalysis were used ERA-Interim; CFSR; MERRA2 and NCEP/NCAR between 1980 and 2010 for the winter extended months (October to March) at a 6-hourly temporal resolution.

The most important results obtained can be summarized as follows:

- The frequency of ARs are higher in the Azores then in the Madeira or Canary s with the interannual variability being present in the 3 archipelagos. In addition, it seems that there is a small decrease in the number of ARs that strike the Azores while for the Madeira and Canary there is slight increase with an outstanding maximum occurring in the extended winter of 2010;

- In the Terceira Island (Azores) the importance of the ARs in explaining the most extreme precipitation (in the last decile where the precipitation is $>90^{\text {th }}$ percentile) values range between near 70\% in Lajes and Agualva;

- Regarding the island of Madeira (Madeira Archipelago) and the Tenerife Island (Canary) the importance of the ARs in in explaining the most extreme precipitation ( $>90^{\text {th }}$ percentile) are lower than for the Azores; 
The 1st International Electronic Conference on the Hydrological Cycle (CHyCle-2017), 12 - 16 November 2017; Sciforum Electronic Conference Series, Vol. 1, 2017

- The use of 4 different reanalysis (ERA-Interim; CFSR; MERRA2 and NCEP/NCAR) for the ARs database allow us to compare if the importance of the ARs in explaining the most extreme precipitation changed when analysing the different reanalysis. Results show that in general the relationship of ARs and extreme precipitation in the European Macaronesian islands is not particularly dependent of the reanalysis that we choose.

Acknowledgments: This work was supported by the project FORLAND - Hydrogeomorphologic risk in Portugal: driving forces and application for land use planning (PTDC/ATPGEO/1660/2014) funded by Fundação para a Ciência e a Tecnologia, Portugal (FCT). A. M. Ramos was also supported by a FCT postdoctoral grant (FCT/DFRH/ SFRH/BPD/84328/2012).

Author Contributions: A.M. Ramos and R. Tomé conceived and designed the experiments; R. Tomé and A.M. Ramos performed the experiments. A.M. Ramos, R. Tomé, R.M. Trigo and M.L.R. Liberato analysed the data and wrote the paper.

Conflicts of Interest: The authors declare no conflict of interest.

\section{Abbreviations}

The following abbreviations are used in this manuscript:

ARs: Atmospheric Rivers

\section{References}

1. Fragoso, M.; Trigo R.M.; Zêzere J.; Valente M.A. The exceptional rainfall event in Lisbon on 18 February 2008. Weather. 2010, 65, 31-35.

2. Zêzere J.; Pereira S.; Tavares A.; Bateira C.; Trigo R.M.; Quaresma I.; Santos P.; Santos M.; Verde J. DISASTER: A GIS database on hydro-geomorphologic disasters in Portugal. Nat.Hazard. 2014, 72, 503-532.

3. Liberato, M.L.R.; Ramos, A.M.; Trigo, R.M.; Trigo, I.F., Durán-Quesada, A.M.; Nieto, R.; Gimeno, L. Moisture Sources and Large-Scale Dynamics Associated With a Flash Flood Event., in Lagrangian Modeling of the Atmosphere (eds J. Lin, D. Brunner, C. Gerbig, A. Stohl, A. Luhar and P. Webley), 2012, American Geophysical Union, Washington, D. C.. doi: 10.1029/2012GM001244

4. Neiman, P.J.; Ralph, F.M.; Wick, G.A.; Lundquist, J.D.; Dettinger M.D. Meteorological characteristics and overland precipitation impacts of atmospheric rivers affecting the West Coast of North America based on eight years of SSM/I satellite observations. J. Hydrometeor. 2008, 9, 22-47.

5. Ralph, F.M.; Dettinger, M.D. Storms, floods, and the science of atmospheric rivers. Eos, Trans. Amer. Geophys.Union. 2011, 92, 265-266.

6. Stohl, A.; Forster, C.; Sodemann, H. Remote sources of water vapor forming precipitation on the Norwegian west coast at $608 \mathrm{~N}-\mathrm{A}$ tale of hurricanes and an atmospheric river. J. Geophys. Res. 2008, 113, D05102.

7. Lavers, D.A.; Villarini, G.; Allan, R.P.; Wood, E.F.; Wade, A.J. The detection of atmospheric rivers in atmospheric reanalyses and their links to British winter floods and the large-scale climatic circulation. J. Geophys. Res. Atmos. 2012, 117.

8. Ramos, A.M; Trigo, R.M.; Liberato, M.L.R.; Tomé, R. Daily Precipitation Extreme Events in the Iberian Peninsula and Its Association with Atmospheric Rivers. J. Hydrometeo. 2015, 16, 579-597.

9. Lavers, D.A.; Villarini, G. The nexus between atmospheric rivers and extreme precipitation across Europe. Geophys. Res. Lett. 2013, 40, 3259-3264.

10. Fragoso, M.; Trigo, R.M.; Pinto, J.G.; Lopes, S.; Lopes, A.; Ulbrich, S.; Magro, C. The 20 February 2010 Madeira flash-floods: synoptic analysis and extreme rainfall assessment. Nat Hazard Earth Sys. 2012, 12, 715-730.

11. Couto, F.T.; Salgado, R.; Costa, M.J. Analysis of intense rainfall events on Madeira Island during the 2009/2010 winter. Nat Hazard Earth Sys. 2012, 12, 2225-2240.

12. Couto, F.T.; Salgado, R.; Costa, M.J.; Prior, V. Precipitation in the Madeira Is- land over a 10-year period and the meridional water vapour transport during the winter seasons. Int. J. Climatol. 2015, 35, 3748-3759. 
The 1st International Electronic Conference on the Hydrological Cycle (CHyCle-2017), 12 - 16 November 2017; Sciforum Electronic Conference Series, Vol. 1, 2017

13. Guan, B., Waliser, DE. Detection of atmospheric rivers: Evaluation and application of an algorithm for global studies. J. Geophys. Res.-Atmos. 2015, 120(24), 12514-12535.

14. Ralph, F.M.; Neiman, P.J.; Wick, G. A. Satellite and CALJET aircraft observations of atmospheric rivers over the eastern North Pacific Ocean during the winter of 1997/98. Mon. Weather Rev. 2004, 132, 1721-1745.

15. Trigo, I.F. Climatology and interannual variability of stormtrack in the Euro-Atlantic sector: A comparison between ERA-40 and NCEP/NCAR reanalyses. Climate Dyn. 2006, 26, 127-143.

16. Trigo, R.M.; Ramos, C; Pereira, S; Ramos, A.M; Zêzere J.L.; Liberato M.L.R. The deadliest storm of the 20th century striking Portugal: Flood impacts and atmospheric circulation. J. Hydrology. 2016, 541, 597-610.

17. Trigo, R.M.; Varino, F.; Ramos, A.M.; Valente, M; Zêzere, J; Vaquero, J; Gouveia, C; Russo, A. The record precipitation and flood event in Iberia in December 1876: description and synoptic analysis. Front Earth Sci. 2014, 2, 1-15.

(c) 2017 by the authors; licensee MDPI, Basel, Switzerland. This article is an open access article distributed under the terms and conditions of the Creative Commons by Attribution (CC-BY) license (http://creativecommons.org/licenses/by/4.0/). 